\title{
Family Involvement in the Special Education Program of West City Central School, Cagayan de Oro City, Philippines
}

\author{
JOANNA RUBY L. PRESENTE \\ joannarubypresente@gmail.com \\ University of Science and Technology of Southern Philippines \\ Cagayan de Oro City, Philippines, 9000
}

\begin{abstract}
A better-quality education and meaningful school environment are achieved when families-teachers-community collaborated as one for a common goal. The study aimed to assess the family involvement in educating the school learners with special needs. This was focused at West City Central School, West I District, Cagayan de Oro City to determine whether the school met the state standards; the existence of a written school policy for families; how families were accepted and treated; and the barriers to families' involvement. A survey research design was used to achieve the objectives. There were 47 respondents: forty (40) parents and seven (7) teachers of the learners with special needs using Random sampling. Survey questionnaires were administered to the respondents and qualitativequantitative data analyses were employed. The findings revealed that families were given opportunities to be involved in school programs and activities; diverse families were welcomed; there were minimal opportunities on family education and training; few school policies were created and explained to the families; and not all families' needs and state standards were met. The recommendations were families should receive adequate and relevant education workshops/trainings; regular family-teacher conferences; and increase the family involvement opportunities in all aspects.
\end{abstract}

Keywords: Special Education, parents' involvement, family relationships, Philippines

\section{Introduction}

The Philippine education today is currently strengthening its thrusts to high quality education by adapting the enhanced and comprehensive curriculum - the $\mathrm{K}$ to 12 for regular programs. This $\mathrm{K}$ to 12 curriculum is also adapted and modified in the Special Education program (SPED) in accordance to the essential and fundamental needs of the school children with special needs at West City Central School, Division of Cagayan de Oro City, Philippines with the belief that it is one of the significant ways towards quality special education program for the school children with special needs. The school caters 92 enrolled pupils with hearing impairment (H.I.), learning disability (LD), mentally challenged (MC), and autism spectrum disorder (ASD). This data showed a remarkable increased number of children with special needs in the school for the past four years.

Accordingly, Senator Miriam Santiago introduced, "the education of special children requires greater commitment because of the existence of distinctive circumstances. It requires the expertise and dedication of a trained staff, the full participation of the supporting characters and, budgetary support for the establishment of the centers, the acquisition of supplies and materials and the installation of other auxiliary aids and services" (Santiago, M.D., Constitution Article 14. Section 1 http://www.senate.gov.ph/lisdata/67445973!.pdf). With this, all schools offering special education program were mandated to religiously and collaboratively implement the program with the stakeholders particularly the family members of the exceptional child. 
Moreover, through the experiences with the stakeholders, the researcher realized that there were primary concerns partnered with challenges and issues in ensuring the delivery of quality special education program. Is the provision in Article 14, section 1 of the Philippine Constitution: "the State shall protect and promote the right of all citizens to quality education at all levels and shall take appropriate steps to make such education accessible to all" fully observed in West City Central School - SPED program of Cagayan de Oro City?

To ensure West City Central - SPED program had taken its appropriate process to make the education accessible, the school must be revisited, assessed and evaluated from time to time. This was one of the specific reasons why the researcher came up with this study. The researcher wanted to conduct a survey on one of the components of a special education program that was the family involvement that had played important roles in the implementation process.

What were the families' needs, concerns and issues regarding the Special Education program? How were these needs, concerns and issues addressed? What were the necessary actions to consider for the betterment of the SPED program? How could the study be of helped in improving the School's SPED program? These were the questions that initially gave the researcher an idea to search on what were really behind of the lapses present in the special education program of West City Central School - SPED program in the Division of Cagayan de Oro City, Philippines particularly in the family involvement component.

\section{Framework}

This study was primarily based on the fundamental aspect of various Philippine or international researches and legal bases on providing appropriate services and high-quality education for individuals with disabilities. Its concepts had come to a realization in providing an appropriate assessment on the special education program being implemented in the community. An assessment procedure and tool that will give an opportunity to have an in-depth study on the quality assurance of the implemented program.

Further, the study was based on the Guiding Principle, Policies and Legal Basis of Special Education of the Philippines, in March 7, 1997, the Department of Education, Culture Sports (now Department of Education) issued DECS Order No. 26, Institutionalization of SPED Programs in All Schools to provide basic education to special children and give them educational opportunities, and to support these: a) The 1987 Constitution of the Republic of the Philippines states in Article XIV, Section 2, education is a basic, legal right of every individual, education being rooted in the concept of equality, the concept of quality of life and grounded in the concept of human rights; b) Republic Act No. 7277 (1995) also known as the Magna Carta for Disabled Persons is to provide disabled persons adequate access to quality education and simple opportunities to develop their skills; and 3) Policies and Guidelines for Special Education (1997) of the Department of Education in Article II Section 2 exhorts "all schools, centers and classes (national or local, public or private, formal or non-formal) established under the educational system of the Philippines for the education of children with special needs".

Several studies revealed the effects of Family involvement to the learner's achievement. Research findings suggest that parents involve themselves in student homework because they believe that they should be involved, believe that their involvement will make a positive difference, and perceive that their children or children's teachers want their involvement (Hoover et al., 2001). This revealed the importance of the parent's involvement to children's success in the school. Their participation in the education of their children have positively contributed by influencing their children to do well in school. Their assistance and support can be in any forms that help increase the performance of the children most especially the children with special needs who tend to be very dependent to their parents or guardians.

Moreover, operating largely through modeling, reinforcement, and instruction, parents' homework involvement appears to influence student success insofar as it supports student attributes related to achievement such as attitudes about homework, perceptions of personal competence, self-regulatory skills (Hoover-Dempsey, 2001). Thus, active family involvement has long been considered to be an important factor related to better outcomes in the education of young children with and without disabilities in inclusive early childhood programs (Berger, 1995; Levy, Kim, \& Olive, 2006; Pérez Carreón, Drake, \& Barton, 2005). 
Parental involvement takes many forms including good parenting in the home, including the provision of a secure and stable environment, intellectual stimulation, parent-child discussion, good models of constructive social and educational values and high aspirations relating to personal fulfilment and good citizenship; contact with schools to share information; participation in school events; participation in the work of the school; and participation in school governance (Desforges \& Abouchaar, 2003).

Results indicate that several family-school-community partnership practices predict an increase in daily attendance, a decrease in chronic absenteeism, or both. The data suggest that schools may be able to increase student attendance in elementary school by implementing specific family and community involvement activities (Epstein \& Sheldon, 2002). Another study revealed that family involvement, family-school partnerships, and school-community partnerships all play important roles in educational programming. Given those factors, each serves a unique function and may address different needs, and distinctions between them are meaningful. Family involvement is characterized by active, meaningful overtures by parents to engage in activities and behaviors at home and at school to benefit their child's learning and development (Fantuzzo, Tighe, \& Childs, 2000). While family-school partnerships extend the concept of family involvement to recognize shared roles and responsibilities among families and schools. Programs that promote partnerships involve collaboration and cooperation between individuals across home and school settings and articulate shared responsibilities (Christenson \& Sheridan, 2001).

Moreover, parental participation and cooperation in their child's educational affairs is related to several outcomes deemed important in educational arenas: increased student achievement and academic performance, stronger selfregulatory skills, fewer discipline problems, better study habits, more positive attitudes toward school, improved homework habits and work orientation, and higher educational aspirations (Aeby, Thyer, \& CarpenterAeby, 1999; Galloway \& Sheridan, 1994; Grolnic \& Slowiaczek, 1994; Ma, 1999; Masten \& Coatsworth, 1998; Trusty, 1999).

In terms of partners and stakeholders, Policies and Guidelines for Special Education Handbook of Special Education Division Bureau of Elementary Education Ministry of Education, Culture and Sports, Manila Philippines (Pascual, Sese \& et.al.,_) Article XII. Parent Education and Community Involvement. Section 1. Parents of Children with special needs are valuable members of the educational team in the program of rehabilitation for independent living of their children.

In addition, parent education shall be a necessary component of the special education program and be made aware of their children's handicaps as well as, the intervention strategies needed to help facilitate each child's academic, social-emotional and communicative development. They shall also be provided with information, and a process of sharing experiences continuously with other parents experiencing similar problems. They shall be directly involved in the planning of educational and special services for their children so they can be of helped and develop confidence in their abilities to cope with, care for and teach their disabled children.

Furthermore, the family of the child shall be involved in the process of rehabilitation. It shall be encouraged as the major rehabilitations' unit. The training of trainers from among community volunteers, including parents and family members of children with special needs, in basic special education techniques as part of the community-based or home-based rehabilitation services shall be conducted to promote programs on early identification and intervention and to enhance home-school relationships.

In summary, this would mean a lot to the success implementation of the special education program. 


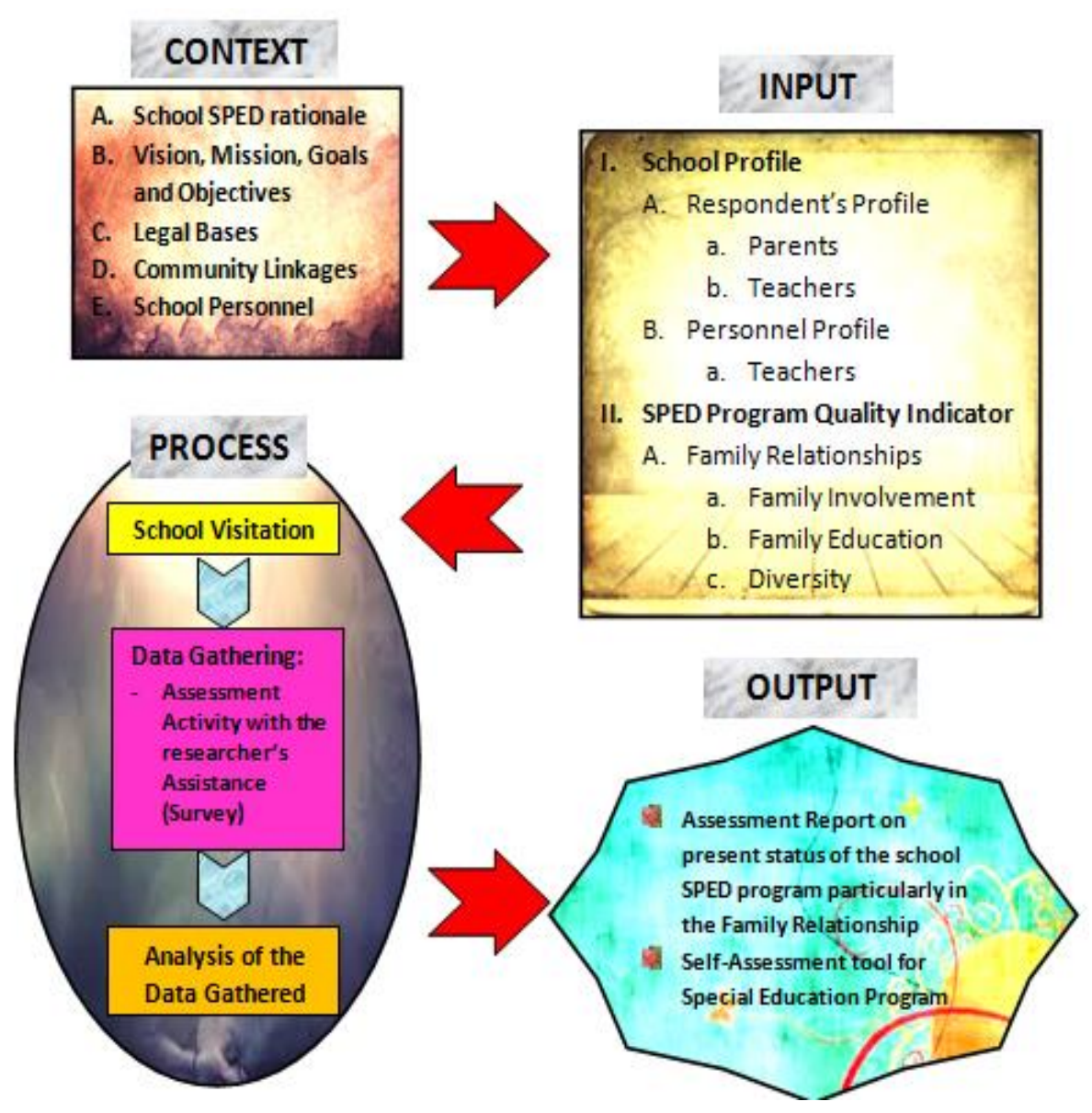

Figure 1. The Schematic Diagram of the Conceptual Framework Showing the Process of the Context-Input-Process-Output

\section{Objectives of the Study}

The objectives of the study were to: 1 ) determine the demographic profile of the respondents a. Parents b. Teachers 2.) Identify the present status of the Special Education Program (SPED) at West City Central School, West I District, Division of Cagayan de Oro City, Philippines in terms of the quality indicators such as family relationships, family education and diversity; 3 ) determine whether school meet the state standards on quality special education program specifically in the quality indicator family involvement 4) determine whether the families were accepted and treated, and whether the barriers to family involvement being addressed.

\section{Methodology}

The methodologies employed in this study were, as follows: the research design, the research setting, sampling procedure, subjects of the study, research instruments, data gathering procedure and the statistical treatment of data.

To achieve the objectives, quantitative-qualitative research design was employed. It particularly involved description of a comprehensive analysis of the quality of special education program offering in West City Central School. Thus, it was only focused in investigating the quality of the special education program in terms of stakeholders' demographic profile and family involvement: 1) Family relationships; 2) Family Education; 3) Diversity. 
Moreover, there were 47 respondents: 40 parents and seven teachers of SPED learners for this study. To come up with the samples, random sampling was used in choosing the parents. There were six parents chosen per class with a total of 43, however, it became 40 because two of them were not able to answer the questionnaires. On the other hand, teachers were chosen through a purposive sampling procedure. The researcher also used a modified special education program assessment tool to gather data and information relevant to the study. The data gathered from the instruments were collected, tabulated, analyzed and interpreted. To have better analysis and interpretation of the data, the study used statistical tools such as frequency, percentage, and mean.

The survey questionnaires were validated and used purposely for the respondents provide relevant data for the study. The respondents' questionnaire set A was used to determine their demographic profiles. The questionnaire set B was administered by both teachers and families (parents) assess the Quality Indicator: Family Involvement. Component A: Family relationships; Component B: Family Education; Component C: Diversity. These indicators were measured and rated through the scoring procedure.

\section{Results and Discussion}

The findings, the analyses, and the interpretation of data of the problems presented in the introduction. The data were presented in tables to assess the quality of special education program of West City Central School, Cagayan de Oro City, Philippines.

In terms of the demographic profile, majority of the family members who were usually present in the school were female parents/guardians composed of 37 out of the 40 respondents. This would connote that female parents were more likely coming to school than male parents. This also supported by Downer, Campus, Mcwayne and Gartner reviews that was focused on the importance of the father involvement. It was emphasized in their articles that from the past 15 years, mothers were much more involved in the education of their children than fathers (Jeynes, 2014). However, fathers still play significant and salient roles that others cannot do.

Table 1. Respondents' Gender Distribution and Years in Participating/Teaching in Special Education (SPED) Program

\begin{tabular}{cc|cc} 
Gender & Distribution of Respondents (Parents) & Gender & Distribution of Respondents (Teachers) \\
\hline Males & 3 & Males & 2 \\
Females & 37 & Females & 5 \\
Total & $\mathbf{4 0}$ & Total & 7
\end{tabular}

\begin{tabular}{cc|cc} 
Years Participating in SPED Program & $\begin{array}{c}\text { Parents } \\
(\mathbf{n = 4 0 )}\end{array}$ & Years Teaching in SPED Program & $\begin{array}{c}\text { Teachers } \\
(\mathbf{n = 7})\end{array}$ \\
\hline More than 8 years & $5 \%$ & More than 8 years & 0 \\
5 to 6 years & $13 \%$ & 5 to 6 years & 0 \\
3 to 4 years & $20 \%$ & 3 to 4 years & $43 \%$ \\
1 to 2 years & $45 \%$ & 1 to 2 years & $14 \%$ \\
Less than 1 year & $18 \%$ & Less than 1 year & $43 \%$
\end{tabular}

On the other hand, female teachers (5) were more in number than male teachers (2) being employed in the school. Females were dominant to pursue teaching as their profession than males. Moreover, among the parents respondents, $18 \%$ (7) have less than a year; $45 \%$ (18) have one to two years; $20 \%$ (8) have three to four years; $13 \%$ (5) have five to six years; and 5\% (2) have more than eight years of experiences participating in the school's special education program. Moreover, this would support the fact that the population rate of new enrollees were increasing because $45 \%$ of the samples were parents of the newly enrolled pupils with disabilities. There are $43 \%$ (3) of the teachers 
teaching three to four years; another $43 \%$ (3) of them are teaching less than one year; and one teacher is teaching in the SPED program for one to two years.

Table 2. Trainings and Seminars Attended by the Respondents

\begin{tabular}{lcl}
\hline Respondents & Frequency & Trainings and Seminars attended \\
\hline Parents & 40 & $\begin{array}{l}\text { Occupational therapy } \\
\text { Talk/seminars on health-related topics such as Dengue, Pulmonary, } \\
\text { etc. }\end{array}$ \\
\hline Teachers & 7 & $\begin{array}{l}\text { Special Education General Concepts } \\
\text { Different Disability } \\
\text { Teaching Strategies for special children }\end{array}$ \\
\hline
\end{tabular}

In terms of the trainings/seminars attended, there were only few education opportunities about Special Education program given to the families of children with special needs. Mostly, families were given trainings on occupational therapy and talk/seminars on health-related topics. This means that parents were not oriented about the whole concept of the program. They have to be guided and informed about the rules and regulations, overview of the special education and other important aspects that are rightfully be discussed with the parents. Additionally, they need more opportunities that will suffice their needs and answers their problems or questions relevant to nurturing and teaching their respective children.

Furthermore, almost all of the SPED teachers were provided with seminars/trainings related to their respective specialization. However, most of them obtained those opportunities years ago. Hence, teachers need to update themselves by joining new educational opportunities. One teacher of the school said, "there were opportunities, but these were limited only to selected teachers and sometimes to selected schools of the Division of Cagayan de Oro...Budget is another issue to us teachers, considering our SPED program is not yet recognized as a center...(anonymous, 2013)". With those statements, teachers were very willing to take the chance of joining educational opportunities but their problem is the budget or funding. The teachers should obtain adequate and updated knowledge related to special education teaching-learning process, as well as the whole SPED program to deliver better quality instruction. However, the subsidy granted per SPED Center (Enclosure No. 1) shall be utilized to support the implementation of the following activities of the SPED Programs as reflected in the approved School Improvement Plan (SIP): Professional upgrading of teachers and school heads (SHs) / supervisors and travel expenses relative to their participation and attendance to activities relevant to the implementation of the program (DO 24, s. 2012). But, this subsidy was only intended for the recognized SPED centers by the central office of Philippine Department of Education. This made the Professional development opportunities of other teachers in non-SPED centers limited to how much the schools can support or the teachers themselves.

Based on the results presented in table 3, most of the families have rated the Component A: Family Relationships as "good". This means that most of the indicators in the component A were found and observed most of the time in most classes throughout the school. There was implementation but it needs minimal effort for improvement. The rating was affirmed and verified by the SPED program teachers. Though, there were minimal problems encountered throughout the implementation process, teachers and families specifically, parents were collaborating each other to preserve the essence of the family relationships in any activities/programs that the school had provided.

Table 3. Respondents Rating for Component B: Family Relationships

\begin{tabular}{cc}
\hline RATINGS & TOTAL NUMBER OF RESPONDENTS \\
\hline POOR (NONE) & 1 \\
FAIR (SOMETIMES) & 4 \\
GOOD (FREQUENT) & 29 \\
EXCELLENT (ALWAYS) & 5 \\
TOTAL & 40 \\
\hline
\end{tabular}


As shown in table 4, the component B: Family Education seemed that most of respondents gave a rating of "fair" quality indicator. This means that the indicators were sometimes found/observe in some classes or in the school. It is not fully implemented and needs more effort for improvement. The teachers also attested that unfortunately, families lack educational opportunities to gain more knowledge particularly on appropriate handling and teaching their children with special needs. With these revelations, it was righteous enough to provide the families with significant education for them to also contribute effectively for their child's success.

Table 4. Respondents Rating for Component B: Family Education

\begin{tabular}{cc}
\hline RATINGS & TOTAL NUMBER OF RESPONDENTS \\
\hline POOR (NONE) & 2 \\
FAIR (SOMETIMES) & $\mathbf{2 3}$ \\
GOOD (FREQUENT) & 14 \\
EXCELLENT (ALWAYS) & 1 \\
TOTAL & 40 \\
\hline
\end{tabular}

Moreover, Component C: Diversity in table 5, families most specially the parents/guardians were treated and well accepted in the school environment in spite of their differences in status, religion, and races. This might be their reasons of giving a "good" rating on the said component. This is evident in school because they were all respected, welcomed and felt belongingness. These were also verified by the teachers. They were really practicing good practices that promote unity despite their individual differences. Thus, all parents were also given opportunities to gain more friends in school.

Table 5. Respondents Rating for Component C: Diversity

\begin{tabular}{cc}
\hline RATINGS & TOTAL NUMBER OF RESPONDENTS \\
\hline POOR (NONE) & 1 \\
FAIR (SOMETIMES) & 7 \\
GOOD (FREQUENT) & $\mathbf{1 8}$ \\
EXCELLENT (ALWAYS) & 13 \\
TOTAL & 40 \\
\hline
\end{tabular}

There were few identified barriers to families' involvement. These are: parents to parents' conflict; parents to teachers' conflict; and the availability of time. These barriers can greatly affect the implementation of the special education program. Parents or Families are the primary individuals that provide support to their children with special needs and make any programs successful. Parental involvement is strongly positively influenced by the child's level of attainment: the higher the level of attainment, the more parents get involved (Desforges \& Abouchaar, 2003). Therefore, without their full support and involvement in any activities in the school, the children's education may be at risk and possibly get a low performance in all learning areas.

The sped management was able to come up with the conflict committee that was composed of PTA officers, teachers as the advisers and administrator as the chairman. The committee served as the frontier in solving problems among the stakeholders and teachers. Adjustment on time schedules was also provided for those parents who were too busy to attend the school activities such as the monthly pahina, parent-teacher conference, etc. Through this, the parents were given opportunities to still participate but during their respective free time.

From the succeeding table, the narrative results affirmed the data gathered for the parent involvement indicator. The school used proactive approach in dealing with parents; and provided activities that addressed some of the needs of the parents. Thus, it promotes positive environment to the parents which also gives a mean towards better quality education for children with special needs. 
Table 6. Respondents Rating for Component C: Diversity

\section{Family Involvement}

Variety of school and community involvement activities

Membership in General Parents-Teachers Association (GPTA),

Homeroom Parents-Teachers Association (HRPTA), other school parents' organization

\begin{tabular}{ll}
\hline Family Education & $\begin{array}{l}\text { Occupational Training } \\
\text { Health related seminars, trainings and symposiums }\end{array}$ \\
\hline Diversity & $\begin{array}{l}\text { Use simple languages that were common to parents/fam } \\
\text { Welcome all individuals }\end{array}$ \\
\hline How families were accepted and & $\begin{array}{l}\text { Parents were accepted and treated well in the school } \\
\text { "welcome" sign boards } \\
\text { treated? }\end{array}$ \\
& School Directory \\
& Family day activities \\
& Monthly "pahina" or Brigada Eskwela Plus \\
& Yearend recognition of active parents \\
& GPTA/HRPTA meetings \\
& Periodic meetings/consultations \\
\hline
\end{tabular}

Occupational Training

Use simple languages that were common to parents/families

Periodic meetings/consultations

Diversity among the parents and learners' cultures, religions, and even perspectives on special education is not new in school. This has also been addressed using variety of strategic planning and activities that caters the different individuals but achieving one common goal for the learners beneficial. Parents' socioeconomic, educational, and linguistic backgrounds strongly affects their decisions how to appropriately participate in providing special education services (Trainor, 2010). Indeed, schools should provide opportunities that does not limit to one particular group of individuals but all among the individuals regardless their differences.

Further, parents often expressed dissatisfaction with the reception that they had received in schools, and their testimonies may help school-based support teams and those responsible for service provision think about appropriate ways of engaging families and encouraging collaboration (Trainor, 2010). With this, school administrators together with the school personnel to work collaboratively in encouraging and motivating the parents to participate in most of the programs of the school. Allow them to realize their important roles and responsibilities in the education of their children. Without their full support, their children may not be able to receive the education that they deserve to receive from the school.

\section{Conclusions}

The findings of this study gave substantial evidences and validated vast researches. The findings revealed that families were given opportunities to get involve in school programs and activities; diverse families were welcomed; there were minimal opportunities on family education only few school policies were created and explained to the families; no written policies related to SPED program were given and explain thoroughly to the teachers and parents; and not all families' needs were met.

The communication among the families is very much significant in working on the progress of a school. It could be in any form of communication either spoken or written. It should be clear, accurate and sent on time - including replies to emails, letters and telephone messages. Follow up on agreed actions; admit when we are wrong and resolve conflict reasonably; and agree to differ where we can't find common ground are also necessary for better improvement on the program.

With the results and findings of the study, the researcher had come up with a conclusion that there would be a better rating than the school sped program presently obtains, only if there were appropriate interventions. An excellent institution will always have its remarkable remarks from the clienteles. 


\section{Recommendations}

On the basis of the findings, conclusions and implications, the following recommendations are presented: a) the families should receive adequate and relevant education workshops/trainings; b) the school should provide regular family-teacher conferences at least once a month; c) the school should also provide more opportunities that promote family involvement in all aspects; d) school administrators should take in account the results of this study and make some actions that will further encourage every family to participate and cooperate well with the school personnel; e) administrators should assess and evaluate the program at least once a year preferably at the end of the school year using the researcher's modified assessment tool; and f) help the sped classes become sped center the soonest the possible.

\section{References}

Allington, R. L., \& Cunningham, P. M. (2002). Schools that work: Where all children read and write. Allyn \& Bacon, 72 Arlington Street, Boston, MA 02116.

Anonymous (1997). "Handbook on Special Education: A Guide for Teachers, Administrators and Service relate Staff'.

Anonymous (2005). Measuring the Quality of Family-Professional Partnerships in Special Education Services. Journal: Exceptional Children. Council for Exceptional Children Publisher. Volume 72, Pages 65-81, Number 1 / Fall. Online Date Wednesday, March 09, 2011

Anonymous (2010). Abs-cbnNEWS.com. Posted at 06/03/2010 5:19 PM | Updated as of 06/03/2010 5:43 PM. http://www.abs-bnnews.com/lifestyle/06/03/10/ deped-congress-pass-special-education-act

Avramidis, Elias \& Norwich, Brahm (2002). Teachers' attitudes towards integration / inclusion: a review of the literature. European Journal of Special Needs Education, Volume 17, Issue 2, pages 129-147 http://www.tandfonline.com/doi/abs/10.1080/ 08856250210129056\#.Uer7C6KQZV8

Carlisle, E., Stanley, L., \& Kemple, K. M. (2005). Opening doors: Understanding school and family influences on family involvement. Early Childhood Education Journal, 33(3), 155-162.

Caspe, M., Lopez, M. E., \& Wolos, C. (2007). Family Involvement in Elementary School Children's Education. Family Involvement Makes a Difference: Evidence that Family Involvement Promotes School Success for Every Child of Every Age. Number 2, Winter 2006/2007. Harvard Family Research Project.

Cook, D.A. (2005). The research we still are not doing: an agenda for the study of computer-based learning. Acad Med.

Desforges, C., \& Abouchaar, A. (2003). The impact of parental involvement, parental support and family education on pupil achievements and adjustment: A literature review. Retrieved December, 11, 2006.

DO 24, s. 2012 (2012). Guidelines on the Utilization of the Support Funds for the Recognized Elementary Special Education (SPED) Centers: Guidelines on the Utilization of the Support Funds for the Recognized Elementary Special Education (SPED) Centers. http://www.deped.gov.ph/orders/do-24-s-2012

Durlak, J.A. \& DuPre, E. P. (2008). Implementation Matters: A Review of Research on the Influence of Implementation on Program Outcomes and the Factors Affecting Implementation.American Journal of Community Psychology. Volume 41, Issue 3-4, pp 327-350. http://link.springer.com/article/10.1007/s10464008-9165-0\#page-1 
Epstein, J. L., \& Sheldon, S. B. (2002). Present and accounted for: Improving student attendance through family and community involvement. The Journal of Educational Research, 95(5), 308-318.

Foss, Jean M. (2001). "Nonverbal Learning Disability: How to Recognize it and Minimize Its Effects”. (ED461238).

Friend, M. (2013). Special education: Contemporary perspectives for school professionals. Pearson Higher Education.

Gargiulo, R. M. (20110. Special Education in Contemporary Society--Media Edition: An Introduction to Exceptionality. Sage Publications.

Hoover-Dempsey, K. V., Battiato, A. C., Walker, J. M., Reed, R. P., \& Jones, K. P. (2001). Parental involvement in homework. Educational Psychologist, 36(3), 195-209.

Jeynes, W. (Ed.). (20140. Family factors and the educational success of children. Routledge.

Navarro, J. R. and F. O. Gallardo (2003). A model of strategic change: Universities and dynamic capabilities. Higher Education Policy, 16(1), 199-212.

Pascual, Dolores M., Sese, Rosa F. \& et. al. (2000). Policies and Guidelines for Special Education Handbook of Special Education Division Bureau of Elementary Education Ministry of Education, Culture and Sports, Manila Philippines.

Pena, D. C. (2000). Parent involvement: Influencing factors and implications. The Journal of Educational Research, 94(1), 42-54.

Trainor, A. (2010). Diverse approaches to parent advocacy during special education home-school interactions: Identification and use of cultural and social capital. Remedial and Special Education, 31(1), 34-47.

Unknown. (2004). Department of Education, Bureau of Elementary Education, Special Education Division, Annual Report, Pasig City, Philippines, Department of Education.

Unknown. (2000). Department of Education, Bureau of Elementary Education, Special Education Division, The national Committee on Education for All, EFA2000: Philippine Assessment Report. Pasig City, Philippines, Department of Education.

Unknown. (2004). Department of Education, Bureau of Elementary Education, Special Education Division, $2^{\text {nd }}$ Quarterly Report, Pasig City, Philippines, Department of Education

Unknown. Ensuring Equal Access to High-Quality Education. Revised. Office for Civil Rights (ED), Washington, DC. 2003-07-00 http://www.gpo.gov/fdsys/pkg/ERIC-ED483023/pdf/ERIC-ED483023.pdf

Unknown. (1992). Magna Carta for Disabled Persons. Dated 24 March 1992. (Official Gazette of the Republic of the Philippines, Vol. 88, No. 18, pp. 2537-2556.) http://dredf.org/international/philippines.html

Xu, Y., \& Filler, J. (2008). Facilitating family involvement and support for inclusive education. The School Community Journal, 18(2), 53-71.

Xu, Y., \& Filler, J. (2008). Facilitating family involvement and support for inclusive education. The School Community Journal, 18(2), 53-71. 